\title{
Building a Project Methodology to Provide Authentic and Appropriate Experiences in Computational Science for Middle and High School Students
}

\author{
Patricia Jacobs \\ Shodor \\ 807 East Main Street, Suite 7-100 \\ Durham, North Carolina 27701 \\ pjacobs@shodor.org
}

\author{
Jennifer Houchins \\ Shodor \\ 807 East Main Street, Suite 7-100 \\ Durham, North Carolina 27701 \\ jhouchins@shodor.org
}

\begin{abstract}
Shodor 4], a national resource for computational science education, has successfully developed a model for middle and high school students to gain authentic and appropriate experiences in computational science. As we prepare students for the 21st century workforce, three of the most important skills for advancing modern mathematics and science are quantitative reasoning, computational thinking, and multiscale modeling. Shodor's Computing MATTERS: Pathways to Cyberinfrastructure program [1], funded in part by the National Science Foundation Cyberinfrastructure Training, Education, Advancement, and Mentoring (CI-TEAM) program, provides opportunities for middle and high school students to explore all three of these areas. One of the wide range of programs offered through Computing MATTERS is the SUCCEED Apprenticeship Program [6].

The overall goal of the SUCCEED Apprenticeship Program 6] is to provide students with authentic and appropriate experiences in the use of technologies, techniques and tools of Information Technology (IT) with a particular focus on computational science and to produce evidence that students become proficient in these IT technologies, techniques and skills. The program combines appropriate structure (classroom-style training and project-based work experience) with meaningful work content, giving students a wide variety of technical and communication skills. The program uses innovative approaches to get students excited about computational science and enables students to grow from excitement to expertise in science, technology, engineering, and mathematics (STEM). Since its beginning in 2005, the SUCCEED Apprenticeship Program [6] has proven to be a successful model for enabling middle and high school students of both genders and of ethnically and economically diverse backgrounds to gain proficiency in STEM while learning, experiencing, and using information technologies.
\end{abstract}

Permission to make digital or hard copies of all or part of this work for personal or classroom use is granted without fee provided that copies are not made or distributed for profit or commercial advantage and that copies bear this notice and the full citation on the first page. To copy otherwise, or republish, to post on servers or to redistribute to lists, requires prior specific permission and/or a fee. Copyright (C) JOCSE, a supported publication of the Shodor Education Foundation Inc.

\section{Keywords}

Computational Science, Mathematics, Science, Technology, Engineering, Modeling, Interactive

\section{INTRODUCTION}

Computing MATTERS: Pathways to Cyberinfrastructure 1], funded in part by the National Science Foundation Cyberinfrastructure Team (CI-TEAM), is an initiative of Shodor that provides a coherent continuum of other-than-schooltime activities from upper elementary grades through college for students to encounter the excitement of discovery, the power of inquiry, and the joy of learning enabled by cyberinfrastructure technologies. Computing MATTERS (Mentoring Academic Transitions Through Experiences in Research and Service) provides explorations that have content-rich context for students to learn computational science, technology, programming, and collaboration. Shodor believes that computing "matters" because quantitative reasoning, computational thinking, and multi-scale modeling are the intellectual heart of 21st century science and therefore are the essential skills needed for the future. Computing MATTERS combines the best of Shodor's efforts from workshops, apprenticeships, and internships and have proven to attract many individuals from groups otherwise underrepresented in STEM (science, technology, engineering and mathematics).

One component of Computing MATTERS is the SUCCEED Apprenticeship Program [6] which provides formal training in computational science and its practical applications within science and the world. In the Apprenticeship Program, middle and high school students are given the opportunity to gain experience in 21st century workforce skills through a coordinated set of apprentice level workshops and projects. Since the program began in 2005, the SUCCEED Apprenticeship Program has provided over 184 students apprentices - with authentic and appropriate experiences in the use of the technologies, techniques, and tools with a particular focus on computational science and its associated areas. During their participation in the program, apprentices study, learn, and demonstrate knowledge of a wide variety of skills ranging from basic numerical methods, scientific programming, model design, validation and verification to research methods incorporating computational science. 


\section{PROGRAM OVERVIEW}

The SUCCEED Apprenticeship Program 6] is only one of a wide range of programs provided by Shodor that helps middle and high school students encounter the excitement of discovery, the power of inquiry, and the joy of learning enabled by advanced technologies. The SUCCEED Apprenticeship Program 6] builds on Shodor's Stimulating Understanding of Computational science through Collaboration, Exploration, Experimentation, and Discovery (SUCCEED) program [3. which provides workshops to introduce middle and high school students to the technologies, techniques, and tools of computational science. Once students have shown interest and excitement for math and science by actively engaging in SUCCEED workshops, they have the opportunity to participate in the SUCCEED Apprenticeship Program 6. In the program, upper middle and high school students work with Shodor staff and other scientists in a learning or "apprentice" mode to use computational science to conduct scientific research, create mathematical models of scientific phenomenon, and use those models to perform a variety of scientific and mathematical explorations.

The overall goal of the SUCCEED Apprenticeship Program 6] is to provide activities, support mechanisms, and mentoring to move students from an excitement for computational science and Information Technology (IT) to becoming an expert in one or more areas of computational science and associated IT components. Throughout the program, apprentices participate in authentic and appropriate experiences in the use of computational science and advanced technologies and techniques to study scientific events within the context of STEM and engage in hands-on activities and projects to demonstrate evidence that they have become proficient in these skills. In addition to the computational and technical skills, the program also enables apprentices to acquire a set of problem solving, collaboration and communication skills identified as valuable for 21 st century workforce.

The program methodology involves workshops, projects and long-term, mentor- supported opportunities for upper middle and high school students in Durham, Raleigh and Research Triangle Park in North Carolina. Significant work has proceeded during the six years of the program to develop both structure and curriculum as well as to evaluate the project methodology of providing opportunities for upper middle and high school students for measuring the effectiveness of authentic experiences in computational science. Shodor has incorporated the "power of inquiry" based on the 5 E's (engage, explore, explain, elaboration, evaluate) 9] learning cycle in the SUCCEED Apprenticeship Program.

\subsection{E's Phases}

\subsubsection{Engagement}

The classes and projects in the SUCCEED Apprenticeship Program [6] are designed to capture the student's attention, stimulate their thinking, and build upon prior knowledge. Apprentices learn and develop various skills such as computer modeling and simulation, computer programming, chemistry, web design, graphics, database design, and engineering. In addition to taking classes, apprentices have the opportunity to work on local, regional, and nationally funded projects.

\subsubsection{Exploration}

Throughout their participation in the program, apprentices are given hands-on assignments and projects that require them to think, plan, investigate and organize collected information. This structure provides numerous opportunities to explore and develop skills which culminates in the development of expertise in one or more areas of computational science.

\subsubsection{Explanation}

Apprentices are involved in analysis of their assignments and projects. They work with instructors and their mentors to ensure their understanding of concepts and processes is demonstrated through their assignments and projects.

\subsubsection{Elaboration}

Apprentices attend classes to learn and increase their knowledge of computational skills and complete assignments and projects to demonstrate and build on a learned skill set. Apprentices have numerous opportunities to demonstrate competence and confidence in the use of technology, critical and analytical thinking skills, and communication and leadership skills. Apprentices work with their mentor to rework assignments until they have successfully completed each one.

\subsubsection{Evaluation}

Throughout the program, the development of the apprentices are evaluated on participation, completion of assignments and projects, journals, surveys, and feedback from their mentor as well as staff. Through the combination of appropriate structure and meaningful work content, the SUCCEED Apprenticeship Program 6] provides outstanding opportunities for students while providing the project staff with the mechanism by which to measure the effectiveness of the program in providing authentic experiences for students to learn computational science and IT.

\section{PROGRAM PARTICIPANTS}

By its third year, the SUCCEED Apprenticeship Program had already surpassed its goal of reaching 100 students, called apprentices, in three years. Overall, a total of 184 middle and high school students have participated in the program. The program consists of students in Durham and the surrounding Research Triangle Park area with a particular emphasis on economically disadvantaged, but highly motivated students. Six years after its beginning, the SUCCEED Apprenticeship Program [6] continues to attract underrepresented groups to STEM fields through its dynamic, hands-on learning experiences and explorations. The program has not focused on a single gender or ethnic group but has successfully recruited both male and female students from diverse racial and ethnic groups and the structure of the program promotes interaction among all groups. Thus, the program does not mirror the atmosphere in many schools where students often cluster together with others of the same ethnic identity and miss the opportunity to work with students from other groups. One indicator of the need for this program is the finding that so many students came from schools where computer science is not available. In 2009, less than $50 \%$ of the students reported that their schools offered a course in computer science. 
Apprentices are recruited from Shodor SUCCEED [3] workshops, local school-based programs and through Shodor's outreach programs. To participate in the program, students must complete an online application, obtain a teacher recommendation, and undergo an interview with Shodor staff. Students are interviewed and evaluated in the following areas: 1) their interest in the program, 2) commitment to the program, 3) teamwork, 4) communication: oral and written, and 6) leadership skills. The program is not limited to talented or high achieving students; the only requirement for admission is a demonstrated interest in STEM. As a result, this leads to a broad range of student outcomes; not all students reach the same level of skill or knowledge at the same pace. However, all students who remain in the program reach a basic level of achievement in a predetermined set of computational science and IT skills and many students go far beyond expectations.

Program Participant Overview:

- Rising 8th - 12th graders

- Students are interviewed and admitted based on their interests in STEM

- Students and parents sign a contract committing their support for their student's participation in the project

- 24 apprentices currently enrolled for 2011-2012

- Apprentices are recruited first from Shodor SUCCEED Scholars Program Workshop 3] and then from other Shodor summer workshops and outreach programs

The Apprenticeship Program 6 started in Fall 2005 with an enrollment of 17 students. By the Fall 2007, the excitement about the program had grown and we had approximately 60 applicants, twice as many applicants as we had space available for in the 2007-2009 cohort. In Summer 2011, The SUCCEED Apprenticeship Program 6] had reached a total of 160 students with $62 \%$ successfully completing the program.

Table 1 shows the number of students that successfully completed the program at the end of each year since it began in 2005. For 2012, we currently have 24 students enrolled in the program. By the end of Summer 2012, the program will have reached 184 students.

\begin{tabular}{|c|c|}
\hline Cohort Year & Students That Completed Program \\
\hline \hline $2005-2007$ & 17 \\
$2006-2008$ & 22 \\
$2007-2009^{\dagger}$ & 32 \\
$2009-2010^{\ddagger}$ & 13 \\
$2010-2011$ & 15 \\
\hline
\end{tabular}

${ }^{\dagger}$ In Fall 2008, program changed from a two year program to a one year program

$\ddagger$ During 2010, the participant enrollment was limited to 15 students

Table 1: Number of Students that Completed the Program by Cohort Year
For apprentice participants, the demographics of the Triangle region, particularly that of Durham and Orange Counties, provides us with an ample recruiting pool, especially for students historically underrepresented in STEM fields. Table 2 demonstrates that the SUCCEED Apprenticeship Program 6] has successfully attracted a diverse population of students.

\begin{tabular}{|c|c|}
\hline Ethnicity & Percentage \\
\hline \hline African-American & $27 \%$ \\
Asian & $21 \%$ \\
Bi-racial & $4 \%$ \\
Caucasian & $42 \%$ \\
Hispanic & $4 \%$ \\
Indian & $2 \%$ \\
\hline
\end{tabular}

Table 2: Participant Ethnicity Demographics

In addition, Table 3 shows that the program has attracted a high percentage of female participants.

\begin{tabular}{|c|c|}
\hline Gender & Percentage \\
\hline \hline Male & $58 \%$ \\
Female & $41 \%$ \\
\hline
\end{tabular}

Table 3: Participant Gender Demographics

\section{STRUCTURE AND CURRICULUM}

Significant work has proceeded throughout the years of the program to develop and evaluate the project methodology of bridging the excitement-expert gap opportunities for upper middle and high school students in the local area. The overall structure of the program is based on providing apprentices with a collaborative, mentor-centered environment modeled after academic research teams, combining classroomstyle skills training with project-based work experience. Through the SUCCEED Apprenticeship Program [6], Shodor has demonstrated that the combination of appropriate structure and meaningful work content can provide students with knowledge in computational science, technical and communication skills, personal interest and motivation, and more pragmatically, a resume-documented depth of experience to pursue an IT-intensive career path.

When the program started in 2005, it was a two-year program with apprentices focusing on an independent learning, self-paced instructional model. Apprentices were provided with written tutorials [5] for learning modeling and simulation as well as other IT skills. Students worked through the tutorials independently with help as needed from peers or mentors. As each tutorial was completed, or when the student felt ready, he/she was given a Challenge problem, to demonstrate attainment of the skill. Although many apprentices thrived in this environment, only about half of them attained the number of IT skills that had been expected.

Based on the stagnant progress of the apprentices, the program was redesigned in 2007 to a one year program to provide more structure, require firmer time commitments, group projects and require that each apprentice spend more time with their mentors. As a result, the current structure, which 
is based on the program redesign, is a successful model involving workshops, individual assignments and team projects to promote the development of understanding of concepts as well as technical proficiency that cannot be reached in short, intensive courses. The current structure has proven that continuous involvement over a period of time reinforces learning and provides sufficient practice in computational science and IT skills for apprentices to reach a level of expertise.

\subsection{Program Structure}

With the current design, each apprentice spends approximately 360 hours in the program over the course of one year (20 hours a month during the school year and 6 weeks during the summer). The 20 hours per month consist of attending 3 workshops per month (Saturdays from 9:00am-2:00pm) and 2 hours of in-office time during the week. In the workshops, computational science and STEM skills are taught in the context of a problem to be solved using hands-on activities and the latest in advanced technology.

Apprentice schedules are organized into 3 modules, ranging from two to three months in length. Apprentices must complete assignments to help them learn and practice using new skills and group projects to demonstrate their knowledge of a given skill set. They must also complete quality assurance through verification and validation testing for all assignments and projects. Participants are asked to re-work any assignments or projects that are incomplete. Our goal is for each student to not only learn but also to become proficient in a given skill set.

The structure of the program focuses on the following five areas:

1. Teaching and supporting the appropriate and authentic use of IT-related technologies, techniques, and tools, with a particular focus on computational science and its associated areas. Throughout the program, apprentices attend workshops, complete assignments and work in collaborative groups on projects. Apprentices attended workshops to gain experience and develop expertise in one or more areas of computational science and associated uses of the technologies, techniques, and tools of IT within the context of STEM. Topics involved general uses of computational science, basic numerical methods, scientific programming, model validation and verification and research methods incorporating computational science. Apprentices have a structured curriculum to learn IT skills such as agent modeling, web design, programming and graphics. Their work is organized into modules of two to three month durations. After a module is completed, apprentices worked in teams to complete assigned projects.

2. Providing mentors to define individual goals and timelines as well to provide guidance through technical difficulties.

In addition to students attending classes, the SUCCEED Apprenticeship program continues to focus on mentoring students. The SUCCEED Apprenticeship program seeks to implement a 'true' apprenticeship program where young people learn from working with and learning from those with more experience. Shodor has approximately 18 staff who have a range of expertise in computational physics, biology, chemistry, and math as well as computer science, system administration, graphics and web design. Each staff member is assigned to mentor 2-3 students. Mentors monitor work progress as well as skill development for individual apprentices. In addition, mentors are responsible for overall research team dynamics, distribution of work and project oversight. Students are required to meet one hour per month with their mentor. Communication between mentors, program coordinator and parents is also ongoing throughout the program.

In addition to monthly meetings, mentors track progress and skill development of apprentices by reviewing the apprentices weekly reflections (questions students have to answer weekly), progress on individual assignments, and projects. Many students receive additional mentoring from staff when they need help understanding and/or completing out-of-class assignments and projects.

3. Providing opportunities for apprentices to work on meaningful projects - local, regional and nationally funded projects.

Throughout the program, apprentices are provided with the opportunity to work on local, regional and nationally funded projects. We continue to partner with local organizations to provide real world experiences for our apprentices' projects. These projects range from working with with local organizations to learning and developing skills for building Shodor's award winning resources such as the Computational Science Education Reference Desk (CSERD) 8] and Interactivate 2] projects. The projects are done as a learning process and thus require intensive guidance to ensure quality workmanship.

4. Providing instruction and opportunities to practice a wide variety of communication skills, including working effectively in a group, interacting with customers and clients, teaching younger students about the technologies, and exercising leadership.

The SUCCEED Apprenticeship program provides opportunities for apprentices to practice a wide variety of communication skills, including working effectively in a group, interacting with clients as well as teaching STEM workshops for younger students. Apprentices have to prepare presentations and present several projects they worked on to demonstrate their knowledge of the skills they learned. These presentations help the apprentices improve their communication skills.

Some apprentices are also given the opportunity to teach workshops about computational science technologies and tools to younger students taking Shodor workshops. In the past, apprentices have taught workshops from system and agent modeling to system administration for both middle and high school students. In addition to teaching, Shodor apprentices are encouraged to exercise leadership by learning how to be effective 
mentors to other students in their own peer group.

5. Providing formal and informal opportunities in critical thinking, including data retrieval, data organization and analysis, application of evidencebased reasoning, problem-solving, creative thinking and decision making.

The SUCCEED Apprenticeship Program provides many opportunities for apprentices to use and demonstrate critical thinking skills. Apprentices must attend workshops to learn computational science and STEM skills. Apprentices are given assignments to practice and hone new skills. In addition, apprentices complete group projects to demonstrate a given skill set. Apprentices work in project teams to integrate various technical skills needed for the completion of their projects. These projects require that each apprentice use a variety of innovative skills as well as problem solving. Apprentices learn and use skills such as modeling, PHP, MySQL, CSS, HTML, Javascript and Google Maps for their projects.

\subsection{Curriculum}

The SUCCEED Apprenticeship Program 6] workshops cover a wide range of topics such as Unix, computational modeling, operating system basics, and web design using HTML and Cascading Style Sheets. In addition, during the summer, apprentices work on projects such as the Computational Science Education Reference Desk (CSERD) [8] and Project Interactivate 2] as well as projects for community organizations. Apprentices also document and assist in teaching SUCCEED [3] workshops at Shodor.

For the Apprenticeship Program [6], Shodor has developed a curriculum that consists of materials and lesson plans designed specifically for use in training middle and high school students in the uses of computational science and technology. The materials are divided into 50-minute lesson plans. The materials are free, adaptable, and available to teachers and students outside of Shodor's programs. The program curriculum and materials are located online 7 .

The apprentice workshop curriculum covers four basic areas:

\section{General Skills}

- How Do You Know?: Students are challenged to think about how they know what they know as a foundation for all other classes in our curriculum. This is the first introduction to Verification (solving the problem right) and Validation (solving the right problem).

- Math and Verbal Skills: Students choose an activity from Interactivate or the National Science Digital Library and learn how to use this activity and the mathematics that it covers. Each activity has a set of Exploration Questions, which the apprentices complete and submit for assessment.

- Office Ethics: Role playing, lectures, presentations, guest speakers, live illustrations, and student interactivity all help the student grasp the concept of office ethics to experience how to work in a business office with integrity and loyalty.

\section{Scientific Modeling}

- AgentSheets and NetLogo: An introduction into agent modeling, using two complementary approaches. Students are introduced to agent behaviors and emergent properties while building a populationdynamics model where agents exchange colors.

- Vensim: An introduction to the concepts of systems modeling. After building a model "on the board" and thinking about the flow of the model away from the computer, students are led through the steps to build and run the model on the computer.

- Excel and Spreadsheets: An introduction to some of the basics of Excel and how to use formulas, slider bars, and graphs to create a model of population growth. This model takes into account factors such as birthrate and carrying capacity. Then students explore how to build a Susceptible, Infected, Recovered (SIR) Model of the spread of a disease, by finding and graphing the number of susceptible, infected, and recovered people in the model over time.

\section{Graphics and Web Design}

- Introduction to HTML: Provides students with a background in Hyper Text Markup Language, and knowledge of basic markup languages and tags. Students learn how to make minor edits to the source of an existing HTML page, and view and understand the results. Students then explore HTML tags and create a simple web page. They learn how to use formatting tags, lists, images, and link tags.

- Introduction to CSS: An introduction to Cascading Style Sheets and why it is useful. Assuming a previous knowledge of HTML, students explore a variety of web designs that use CSS for content presentation and management, learning how to add CSS to the header of an existing page.

- Introduction to Visualization: Students first learn GIMP and the concept of raster graphics. It covers basic image manipulation concepts, filters, and saving for the web. Students will learn what a raster/bitmap graphic is as opposed to a vector graphic. They manipulate images in GIMP, selecting, moving, retouching. Then Inkscape and vector graphics are presented. Students explore simple vector graphics, create basic shapes and text, as well as use the Fill and Stroke palette to change the color of an object.

\section{Programming and System Administration}

- Introduction to Programming: After mastering modeling and visualization, the Shodor approach then introduces the high level idea of programming concepts. It is not specific to a particular computer language, environment, or other such limitations. The goal is to teach the ideas behind programming, not to teach programming itself. 
- Language Specific Workshops: Multiple workshops are offered for a range in languages including scripting (Python, PHP, Perl), modeling (NetLogo), and more general-purpose languages (C, Fortran, $\mathrm{C}++$, Java). Each workshop serves as a review of modeling while being an introduction into scientific programming. Students are introduced to agent behaviors and emergent properties while building a variety of models across various scientific areas. The goal is to emphasize similarities of the languages while recognizing underlying comparative strengths and weaknesses of procedural and object-oriented approaches.

- System Administration: This workshop introduces students to the idea of operating a computer via the Unix command line, as well as some of the basic concepts required to understand the Unix way of doing things. Command language, scripting, security, data management, remote monitoring, and batch execution are covered.

In addition to learning computational science and IT skills, a math component has been incorporated into the Apprenticeship Program curriculum 7]. Finding that many students struggled with certain aspects of the program because of weak math skills, Shodor dedicated one Saturday a month to teaching and helping apprentices learn and enhance their math skills. The math component not only focuses on helping apprentices improve their math skills but also helps them learn math as an integral part of their education in computational science. For example, the apprentices learn the mathematics behind a disease spread model, such as probability, functions, and data analysis. The program helps apprentices gain a deeper understanding of mathematics as they learn to apply it to real world situations through the use of computers.

\section{EVALUATION}

Evaluation of the SUCCEED Apprenticeship Program 6] focuses primarily on providing authentic experiences for middle and high school students to develop computational science and IT skills and the assessment of each student in the use of those skills. Evaluation is an ongoing process embedded into all aspects of the program and is related to the pedagogical approach of engaging students in experiences directed toward acquiring IT skills and knowledge. Evaluation tools used required that each apprentice maintain a journal, completed assignments, and participated as part of a team in completing a succession of projects that required application of learned skills. Apprentices are required to rework assignments and projects until they produced work that met standards set by their mentors.

Since the program began in 2005, an extensive evaluation process has helped us continually improve the effectiveness of the program's structure and curriculum. Evaluation data includes skills assessments, students participation, completion of assignments, personal journals, responses to routine surveys, and feedback from staff. Additionally, periodic interviews with students are conducted to track their attitudes and career plans. Shodor staff continually monitor, observe, and interact with apprentices seeking ways to improve the program.

As a result of their participation in the SUCCEED Apprenticeship Program 6], students showed an improvement in their IT and soft (presentation, teamwork, teaching, etc.) skills. In addition to informal assessments and feedback from the Shodor staff mentors, apprentices performed selfassessments at the beginning of the program, beginning of summer, and end of summer. The apprentices rated themselves on a scale of 1-5 on a range of IT skills. A rating of 4-5 is deemed an expert and able to teach the skill to others. A rating of 3 indicates competent use of the skill in projects assigned and completed. A lower rating indicates that an apprentice can use the skill with help but has not yet become competent to apply it independently. Table 4 shows that students in the 2010-2011 cohort had an improvement of between $16 \%$ to $75 \%$ in their computational science and IT skills when they completed the program.

\begin{tabular}{|l|c|}
\hline Skill & Percentage Improved \\
\hline \hline HTML/CSS & $25 \%$ \\
Graphics & $25 \%$ \\
PHP & $16 \%$ \\
MYSQL & $50 \%$ \\
Subversion & $75 \%$ \\
Object-Oriented Programming & $75 \%$ \\
AgentSheets & $33 \%$ \\
Netlogo & $33 \%$ \\
Excel & $33 \%$ \\
Vensim & $16 \%$ \\
Technical Writing & $25 \%$ \\
Unix Commands & $42 \%$ \\
Team Work & $16 \%$ \\
Presentation Skills & $16 \%$ \\
Self Confidence & $16 \%$ \\
Teaching & $16 \%$ \\
\hline
\end{tabular}

Table 4: Percent of Students that Improved from Level 3 or Lower to Level 4 or Higher

\section{SUMMARY}

The SUCCEED Apprenticeship Program 6. provides a structured learning environment that evolved as experience in managing the program was gained over the program's six year period. During the program, apprentices learn skills such as computer modeling and simulation, HTML, CSS, Graphics, PHP, MYSQL, AgentSheets, NetLogo, Excel, System Administration, as well as Technical Writing and Presentation skills. The structure includes classes, homework, teamwork, and independent work. Apprentices are held accountable for time on a task, attendance at classes, project completion, and development of workplace skills.

An evaluation of the value added and the measurability of the Apprenticeship program 6] is assessing the extent to which the appropriate structure and meaningful work content effectively develops students to become an expert in the areas of computational science and associated IT components. We continue to evaluate the program's success and to improve the effectiveness of the program's structure and curriculum. 
Since the program began in 2005, the evaluation process has helped us continually improve the effectiveness of the program's structure and curriculum. The Apprenticeship program 6], as it has developed over the last six years, enables students of diverse backgrounds to gain computational science and IT proficiency. We have shown that students of diverse racial and ethnic backgrounds have gained proficiency in a wide range of skills. The percentage of underrepresented groups remains high among the apprentices who persist through the entire program. In addition, many students who have participated in the program expect to have IT-related careers and thus will take their places in ITintensive workplaces as they move into the adult workforce. An interesting and unusual aspect of the population of apprentices in the program is the high percentage of African American females. We believe that interaction between students of diverse ethnicities and genders in a learning environment where respect for all students, as well as mentors and instructors, is the norm and is expected and required has been an important aspect of the program. The results of the assessment by mentors who have been actively engaged with apprentices indicates that, with very few exceptions, all apprentices who persisted in the program are able to use IT skills learned at an expert or practical level in any environment where these skills are required.

The following summarizes the evaluation results and effectiveness of the SUCCEED Apprenticeship Program 6] methodology:

- The program was notably successful in recruiting students of diverse racial and ethnic backgrounds and both genders. Since the program began in late 2005, a total of 184 students, including the current cohort, have been admitted into the program and a total of 123 students will have successfully completed the program by Summer 2012. The project has been successful not only in recruiting a diverse group of students but also in maintaining diversity in the groups who have persisted through the full program.

- The majority of those who completed the program have maintained a strong interest in science, technology, engineering and math as evidenced by their plans to pursue careers in one of the STEM areas. Persistence in intention to pursue a career in STEM was used as an indicator of enthusiasm and was measured by three successive interviews or surveys of apprentices conducted (a) soon after entry into program, (b) midway through program, and (c) at completion of the program. In addition, there were others who reported that they had decided to pursue a career in STEM or had been prompted to rethink their career plans.

- Apprentices who completed the program are equipped to continue their education and eventually enter the workforce with unusual proficiency in such IT skills as Java, Unix, HTML/CSS, Graphics, PHP, ObjectOriented Programming, MYSQL, AgentSheets, NetLogo, Excel, and Vensim. Those who complete the program become proficient in a number of more advanced IT skills that require a higher level of planning, thinking, and execution.
- In addition to acquiring technical skills, apprentices also acquired significant skills in professional ethics, technical writing, presentation skills, team work and self confidence.

- Data and observations collected over the six years have allowed us to identify certain elements of the program that have promoted and enabled attainment of proficiency in IT by middle and high school students who have an initial interest in IT and STEM. The main elements are: the long term involvement of participants, the recruitment policy of requiring only interest in learning, using structured learning experiences, and mentoring of students with ongoing evaluation.

Shodor 4] programs provide opportunities for students to progress from excitement to experience to expertise through workshops, apprenticeships and internships. Our students gain skills that are equipping them for the 21st Century workforce. Many students from the SUCCEED Apprenticeship Program [6] have continued their interest in STEM by becoming interns at Shodor and accomplishing great achievements. Here we will mention several students who progressed from workshop student to apprentice and then to intern. It should be noted that all of these students have received accolades for their achievements and are also all from groups historically underrepresented in STEM.

In 2010, The National Center for Women and Information Technology (NCWIT) selected Shodor intern, Ada Taylor, as a recipient of the National NCWIT Award for Aspirations in Computing and Krista Katzenmeyer, another Shodor intern, was a semi-finalist for the award. Both Ada and Krista started as workshop students that developed into apprentices in the SUCCEED Apprenticeship Program [6] at Shodor [4]. Additionally, Ada participated in the Conrad Spirit of Innovation Competition with her team, called Unisecurity, from the North Carolina School of Science and Math, taking first place in the competition. Held at the NASA-Ames Research Center, the competition was intended to develop mobile applications based in security.

Yet another Shodor intern, Alex Revelle, received the Student Leadership Award in Science, Mathematics, and Technology Education by the North Carolina Science, Mathematics, and Technology (SMT) Education Center. Alex began his work at Shodor as a workshop student, completed Shodor's Apprenticeship Program [6] and ultimately became an intern. As an intern, Alex became involved in Shodor's outreach efforts by helping to teach workshops in the surrounding community. Like Alex, intern Cameron Aviles became involved with teaching Shodor outreach workshops. Cameron and another apprentice from his cohort year, Maya Gouw, both won the Duke University Durham Student of the Week award for their outstanding work.

The SUCCEED Apprenticeship model is a straightforward application of good educational principles, carried out in a work-oriented environment by staff with experience and expertise in information technology as well as a deep understanding in the areas of science and mathematics. This model does not offer a quick and easy solution to training middle and high school students to be competent in techni- 
cal and/or workplace skills but it attests to the value and efficacy of making a long term commitment to a group of students diverse in both background and ability and helping them develop the skills they will need for the 21 st century workforce.

\section{ABOUT SHODOR}

Shodor 4] is a non-profit education and research organization located in Durham, N.C. Shodor is dedicated to mentoring and providing hands-on learning for students to master 21st century workforce skills, building high quality on-line interactive tools and curriculum for mathematics and science, and supporting the professional development of educators by providing training on the appropriate and effective use of computer technologies and content in the classroom. Special emphasis is placed on hands-on learning for students to gain experience in computational technology by assisting in the development of models and simulations used by educators.

Shodor's online educational resources and materials reach upward of 4 million page views per month. In addition to developing interactive models, simulations, and educational tools, Shodor serves students and educators nationwide directly through workshops and other hands-on experiences. Shodor offers innovative workshops helping faculty and teachers incorporate computational science into their own curricula or programs. For students from middle school through undergraduate, Shodor offers workshops, apprenticeships, internships and outreach programs that explore new approaches to math and science education through computational science.

\section{ACKNOWLEDGEMENTS}

The funding support for Project SUCCEED 3 and the SUCCEED Apprenticeship Program 6] was provided by the National Science Foundation's Innovative Technology Experience for Students and Teachers program (ITEST 0525178), the Burroughs Wellcome Fund, the Department of Education, and the Cyberinfrastructure Training, Education, Advancement, and Mentoring program (CI -TEAM 1041391). The Project PI, Dr. Robert Panoff, is founder and Executive Director of Shodor and has been a consultant at several national laboratories. He is also a frequent presenter at NSF-sponsored workshops on visualiztion, supercomputing, and networking, and continues to serve as consultant for the education program at the National Center for Supercomputing Applications at the University of Illinois at Urbana-Champaign. He has served on the advisory panel for Applications of Advanced Technology program at NSF. Dr. Panoff has dedicated his life to promoting and improving science and mathematics education in North Carolina and throughout the country. The Project Evaluator, Dr. Ann Howe, now an independent evaluation consultant, retired as Chair of the Department of Curriculum and Instruction at the University of Maryland after serving as a head of the Department of Mathematics and Science Education at North Carolina State University and Professor of Science Teaching at Syracuse University. She has had extensive training in both quantitative and qualitative research methods which she used in her own research and as advisor to doctoral students. Over the past twenty years, she has had broad experience as evaluator on numerous projects in science, mathematics and technology education sponsored by NSF and other agencies and foundations.

\section{REFERENCES}

[1] Computing MATTERS: Mentoring Academic Transitions Through Experiences in Research and Service. http://www. computingmatters.org/

[2] Project Interactivate. http://www. shodor.org/interactivate/

[3] Project SUCCEED: Stimulating Understanding of Computational science through Collaboration, Exploration, Experimentation, and Discovery. http://www.shodor.org/succeed

[4] Shodor: A National Resource for Computational Science. http://www. shodor.org/

[5] Shodor Tutorials. http://shodor.org/tutorials/

[6] SUCCEED Apprenticeship Program. http://www.shodor.org/succeed/apprenticeships/

[7] SUCCEED Apprenticeship Program Curriculum. http://www.shodor.org/succeed/curriculum/ apprenticeship/.

[8] The Computational Science Education Reference Desk. http://www.shodor.org/refdesk/

[9] R. Bybee, J. Taylor, A. Gardner, P. Scotter, J. Powell, A. Westbrook, et al. The BSCS 5E instructional model: Origins, effectiveness, and applications. Technical report, Office of Science Education, National Institutes of Health, 2006. 